\title{
CARACTERÍSTICAS DE VENTILAÇÃo DO NÚCLEO CUNHA, PARQUE ESTADUAL DA SERRA DO MAR, SP
}

\author{
VENEZIANI, Yuri - yuri.veneziani@usp.br \\ Mestrando - Dep. Geografia - FFLCH - Univ. de São Paulo - São Paulo \\ GALVANI, Emerson - egalvani@usp.br \\ Dep. Geografia - FFLCH - Univ. de São Paulo - São Paulo \\ RANZINI, Maurício - ranzini@if.sp.gov.br \\ Instituto Florestal - São Paulo
}

\section{RESUMO}

A pesquisa objetivou analisar a evolução anual e mensal do regime de velocidades e direções de ventos, e as calmarias com dados obtidos entre 1980 e 1988 . No período estudado tanto as direções, quanto as velocidades de vento não apresentaram regularidade ou ciclicidade anual de escoamento. Constatou-se que as direções resultantes apresentaram distribuição homogênea pelos diferentes quadrantes, com pequena predominância de fluxos de W (17\% do tempo), e menor participação de ventos orientais. Anualmente, houve alteração do regime a partir de 1984, com ascendência de fluxos de N, NW e W (totalizaram mais de $60 \%$ em 1986), e diminuição dos demais quadrantes. Mensalmente a distribuição entre os fluxos dos 8 quadrantes foi regular, concentrado na direção oeste, fato que se contrapôs a habitual evolução sazonal. Foram preferenciais as participações de ventos continentais nos meses de primavera, verão e outono, enquanto mostrou-se crescente os fluxos marítimos nos meses mais frios. 0 regime de velocidades obteve média anual baixa, de $2 \mathrm{~m} \cdot \mathrm{s}^{-1}$ concentrado na faixa de 1 a $1,5 \mathrm{~m} . \mathrm{s}^{-1}$, com tendência positiva impulsionada pelos resultados de 1986 e 1987 . As velocidades médias mensais mais intensas tenderam a se concentrar no verão, com pico em janeiro $\left(2,16 \mathrm{~m} . \mathrm{s}^{-1}\right)$; enquanto as mais amenas, no início da primavera, representado por setembro $\left(1,7 \mathrm{~m} \cdot \mathrm{s}^{-1}\right)$. Os períodos de calmarias foram abundantes no local (58\% do tempo), com pico em 1986 (70\%), e tendência anual positiva. Sazonalmente, percebeu-se predomínio da movimentação do ar entre o início da série histórica e o ano de 1982, sendo que entre 1983 e meados de 1984 foi um intervalo de transição, e a partir de 1985 houve predomínio total de calmarias, apenas cessado no último semestre da série. A leitura integrada dos dados apontou para uma correlação entre a ampliação dos intervalos de calmarias e a maior participação de fluxos continentais.
\end{abstract}

Palavras-chave: Ventos, Núcleo Cunha

FEATURES VENTILATION IN NUCLEO CUNHA, STATE PARK OF SERRA DO MAR, SP

ABSTRACT: This research intended to analyze the annual and monthly evaluations of wind velocities and directions, and calms moments, from data obtained between 1980 and 1988, in Cunha, São Paulo. Wind directions and velocities studied during this period didn't present regularity or cycle behavior in annual flows. In global average, the predominant directions were homogeneously distributed among eight different sectors, with little west flow predominance (17\% of the time), and smaller contribution of oriental directions. Annually, there were changes in wind regime since 1984 from N, NW and W flows started to rise (added more than 60\% in 1986), and others quadrants decreased. Springs, summers and autumns presented considerable continental wind contributions, while, in cooler periods, the maritime flows were crescents. The wind speed data obtained low annual average, $2 \mathrm{~m} . \mathrm{s}^{-1}$, concentrated in the range of 1 to $1,5 \mathrm{~m} \cdot \mathrm{s}^{-1}$, with positive trend driven by the results of $1986 \mathrm{e} 1987$. The monthly regime most intensive wind speeds tended to concentrate in summer, with peak in January $\left(2,16 \mathrm{~m} . \mathrm{s}^{-1}\right)$. In other hand, mild speeds were grouped in springs, mainly in September $\left(1,7 \mathrm{~m} \cdot \mathrm{s}^{-1}\right)$. Calm periods were abundant in the region (58\% of the time). With positive annual tendency these data took peak in 1986 with $70 \%$. Seasonally, there was predominance of air in motion between the beginning of the historical series and the year of 1982. Between 1983 and 1984 there was a transition interval. Finally from 1985, calm periods were bigger and dominated the regime interrupted just in the last semester of the series. The integrated interpretation of the data pointed out to a correlation between the expansion of calm intervals and the bigger contribution of continental flows.

Keyword: Wind, Núcleo Cunha 


\section{INTRODUÇÃO}

Desde as contribuições da termodinâmica e da dinâmica dos fluidos para a climatologia, constituintes fundamentais e primordiais da meteorologia, os estudos de ventilação e o mapeamento de campos de vento adquiriram outras perspectivas e interfaces naquela ciência. Considerando a abordagem geográfica do clima são recorrentes pesquisas que se dedicam a fornecer instrumentos práticos e resultados aplicáveis no planejamento espacial e estratégico, que interfiram no cotidiano da sociedade, sendo este um importante viés da climatologia atual (SANT'ANNA NETO, 2008).

Galvani et al. (1999) destacaram que em ambientes agrícolas informações relativas à velocidade e direção do vento permitem estimar a disseminação natural de sementes; ou ainda a correta fixação e o ideal posicionamento de quebra-ventos, situando-os a barlavento dos fluxos predominantes e mais intensos, particularmente, em regiões onde sistemas frontais são frequentes.

Já em áreas urbanas, a dissipação e a dispersão de poluentes e aerossóis ocasionadas pela turbulência troposférica são, recorrentemente, pontuados como questões centrais dos estudos de clima urbano. Em microescala, abordar o conforto térmico em áreas metropolitanas tem sido importante para construção de edifícios climaticamente mais eficientes (PEREIRA; ANGELOCCI; SENTELHAS, 2002). Esses autores chamam atenção ainda para outra importante esfera dos estudos de vento relativos ao potencial eólico para geração de energia. Diversos estudos técnicos de viabilidade energética têm sido gerados, particularmente, por institutos e órgãos do Nordeste brasileiro.

A despeito desta variedade de escopos práticos, o vento, tal como qualquer outro componente atmosférico integra a multivariedade e a incessante dinamicidade climática, produzidas pelas infinitas possibilidades de relações entre os atributos ao longo do tempo. Diferentemente dos demais elementos, o dado de vento caracteriza-se como uma grandeza vetorial, com intensidade e sentido (AYOADE, 1986). Tal grandeza física induz a abordagens estatísticas e climáticas mais cautelosas, de forma a não reduzir os dados de vento a qualidades climáticas, mas, sim, permitir que expressem os mecanismos "reais" de circulação atmosférica em estudo (AZEVEDO, 2004).

Associado a essas dificuldades oriundas da natureza do dado, é primordial ter em mente que as características espaciais de um regime climático ocorrido sobre um determinado local multiplica as possibilidades de consórcios entre as variáveis atmosféricas, tornando ainda mais complexa sua abordagem.

Em relação às escalas, aspectos climáticos zonais, regionais e locais se articulam sucessivamente, hora valorizando circulações menos abrangentes, hora com predomínio das mais abrangentes. Em tese, dados de velocidade, direção de ventos e calmarias expressam tais relações e, de modo geral, nos permitem analisar a intrincada circulação atmosférica ocorrida sobre a estação, cuja altura em relação à superfície, por exemplo, pode dilatar as contribuições de sistemas de circulação localmente produzidas, ou favorecer aspectos de escala regional ou zonal, como pontua Azevedo (2004).

Os diversos estudos realizados na região litorânea do sudeste (PEZZOPANE, 1996; WALDHEIN e SANTOS, 2004; LIMA e GALVANI, 2008) e em áreas interiores do Estado paulista (FARIA, 2000; LÓPEZ, 2001; AZEVEDO, 2004; MUNHOZ e GARCIA, 2008; SANSIGOLO, 2008; HAKCEROTT e GANDÚ, 2010) demonstraram forte influência da brisa marítima na maior parte do dia, mesmo em setores localizados a dezenas de quilômetros afastados da costa. Os resultados relativos à direção predominante, frequentemente, apontaram $E, S E$ e $S$ como quadrantes de maior participação. Em áreas litorâneas, o período noturno se caracterizou pelo predomínio dos quadrantes opostos, em função de mecanismo de brisa terrestre.

O cenário complexo para a pesquisa sobre ventos impõe aos estudos climáticos decisões metodológicas diversificadas, seja por meio do uso de modelos matemáticos consagrados, seja pela aplicação de procedimentos descritivos de análise de dados.

$\mathrm{O}$ estudo que aqui se apresenta teve como objetivo analisar quantitativamente e qualitativamente os ventos do Núcleo Cunha do Parque Estadual da Serra do Mar em São Paulo, a partir de dados obtidos entre 1980 e 1988. Realizou-se a leitura de cada um dos módulos de vento e das calmarias, para, posteriormente, integrar tais informações e derivar dados inéditos no esforço de interpretá-los como um todo. Utilizou-se a estatística descritiva básica associada à leitura de unidades cronológicas coerentemente fundamentadas na 
sazonalidade esperada para a região, conforme Monteiro (1969), Tarifa (1975) e Nimer (1989), gerando informações suficientes para analisar o regime de ventos. Como objetivos subsequentes, destaca-se a geração de informações sobre a circulação atmosférica na região de Cunha na Serra do Mar, incrementando o acervo de informações climatológicas do Laboratório de Hidrologia Florestal Eng. Agr. Walter Emmerich (L.H.F.W.E.).

\section{MATERIAL(AIS) E MÉTODO(S)}

a. A região de estudo

A estação meteorológica da qual se extraíram os dados de vento integra o L.H.F.W.E., inserido no Núcleo Cunha do Parque Estadual da Serra do Mar (PESM). Localizado no extremo norte deste Parque Estadual, é administrado pela Fundação para Conservação e Produção Florestal do Estado de São Paulo, e integra a maior área contígua de preservação de Mata Atlântica do Brasil (PLANO DE MANEJO DO PESM, 2008).

Situado dentro do município da Estância Climática de Cunha $\left(1.410 \mathrm{~km}^{2}\right)$, em São Paulo, o Núcleo dista $15 \mathrm{~km}$ em linha reta da costa e abrange uma área de 2.854 hectares (FIGURA 01 ). As altitudes variam entre $1.040 \mathrm{~m}$ a $1.160 \mathrm{~m}$, entre vales e interflúvios bem dissecados.

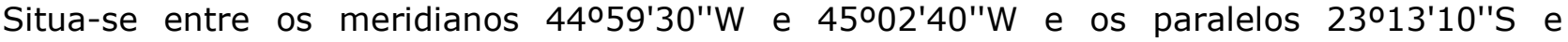
$23^{\circ} 17^{\prime} 28^{\prime \prime S}$, estando, portanto, a menos de dez minutos norte do trópico de Capricórnio, em zona intertropical, sujeito à condição transicional climática entre sistemas extratropicais e tropicais (TARIFA, 1975; MONTEIRO, 1969).
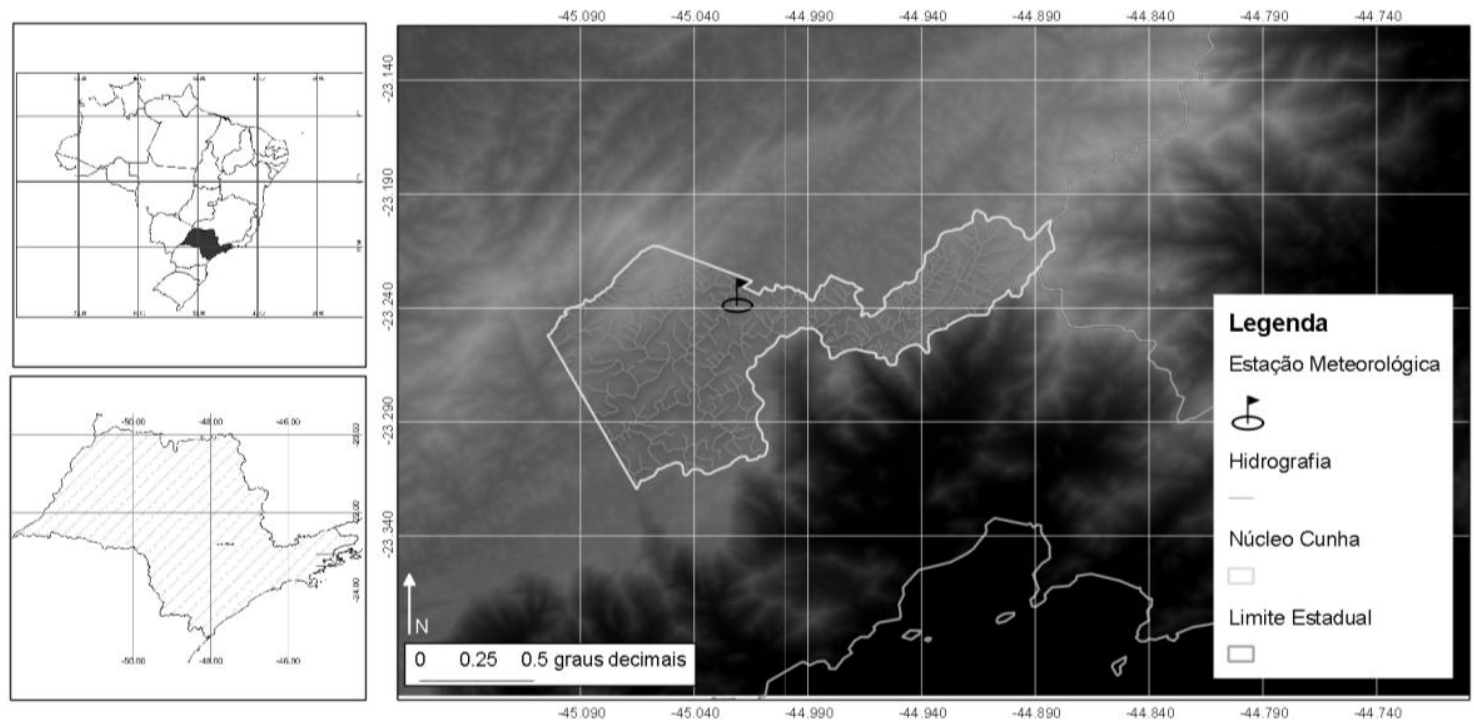

Figura 01 - Localização regional do Núcleo Cunha (PESM) e da estação meteorológica em seu contexto.

Fonte: Imagens do Shuttle Radar Topography Mission.

O Núcleo Cunha se caracteriza pelo complexo e singular contexto geológicogeomorfológico, hidrográfico e climático que o abrange (QUADRO 01). 
ISSN: 1980-055x (Impressa) 2237-8642 (Eletrônica)

Quadro 01 - Aspectos do meio físico: suas classificações e principais características, conforme os autores.

\begin{tabular}{|c|c|c|}
\hline $\begin{array}{l}\text { Esfera / } \\
\text { Fonte }\end{array}$ & Classificação & Principais Características \\
\hline $\begin{array}{l}\text { Geologia / SÃO } \\
\text { PAULO (2005) }\end{array}$ & $\begin{array}{l}\text { Domínio do Terreno } \\
\text { Embú }\end{array}$ & $\begin{array}{l}\text { Gênese: separação de Gondwana. Falhamentos } \\
\text { estruturas petrográficas pré-cambrianas dobrada } \\
\text { predominam, constituídas de formações ígneas } \\
\text { (blocos graníticos/granitóides) e metamórficas } \\
\text { (migmatitos/gnaisses) }\end{array}$ \\
\hline $\begin{array}{l}\text { Geomorfologia } \\
\text { / ROSS e } \\
\text { MOROZ (1997) }\end{array}$ & $\begin{array}{lr}\text { Província } & \text { Planaltica } \\
\text { Orogênica } & \text { do } \\
\text { Atlântico } & \end{array}$ & $\begin{array}{l}\text { Planalto serrano escarpado constituídos por } \\
\text { morros mamelonares extensos, altos e } \\
\text { orientados. Dissecação intensa conferindo } \\
\text { profundos vales em "v", interflúvios estreitos e } \\
\text { declividades entre } 20 \% \text { e } 30 \%\end{array}$ \\
\hline $\begin{array}{l}\text { Pedologia / } \\
\text { FURIAN e } \\
\text { PFEIFFER } \\
(1986) ; \text { CICCO } \\
(2004) ; \\
\text { ARMANI } \\
(2010)\end{array}$ & $\begin{array}{l}\text { Latossolo vermelho- } \\
\text { amarelo (fase rasa) } \\
\text { ou latossolo } \\
\text { vermelho amarelo } \\
\text { câmbicoratura) } \\
\text { nomenclatura) }\end{array}$ & $\begin{array}{l}\text { Tendência constante à intemperização e } \\
\text { pedogeneização, e intensos processos de erosão } \\
\text { superficial. Profundidades significativas para os } \\
\text { horizontes A e O; e B em menor escala. Estrutura } \\
\text { madura, textura silto-argilosa, alta porosidade, } \\
\text { abundantes canais biológicos, boa permeabilidade } \\
\text { hídrica }\end{array}$ \\
\hline $\begin{array}{l}\text { Vegetação / } \\
\text { CICCO (2010) }\end{array}$ & $\begin{array}{lr}\text { Floresta } & \text { Ombrófila } \\
\text { Densa } & \text { em } \\
\text { regeneração. Mata } & \text { Mtlântica Secundária }\end{array}$ & $\begin{array}{l}\text { Consideradas matas secundárias, as florestas no } \\
\text { interior da unidade de conservação (UC) estão em } \\
\text { estado avançado de regeneração }\end{array}$ \\
\hline $\begin{array}{l}\text { Hidrografia / } \\
\text { ARMANI (2004, } \\
2010)\end{array}$ & $\begin{array}{l}\text { Sub-paralelo } \\
\text { dendrítico }\end{array}$ & $\begin{array}{l}\text { Drenagem encaixada seguindo os controles } \\
\text { geológicos que conferem morros sub-retilínios e } \\
\text { paralelos. Dentre os principais cursos da região } \\
\text { estão o Rio Paraibuna e o Rio Bonito }\end{array}$ \\
\hline $\begin{array}{l}\text { Clima / LUIZ } \\
(2008), \\
\text { ARMANI } \\
(2010)\end{array}$ & $\begin{array}{l}\text { Tropical, } \\
\text { classificação Köppen } \\
\text { Cwb, } \\
\text { constantemente } \\
\text { úmido sem } \\
\text { sazonalidade } \\
\text { definida }\end{array}$ & $\begin{array}{l}\text { Precipitação média de } 1.998 \mathrm{~mm} / \text { ano, média } \\
\text { térmica de } 16,8^{\circ} \mathrm{C} \text {. A associação entre o sistema } \\
\text { de brisas e o relevo escarpado favorecem a } \\
\text { formação de nebulosidade e precipitações } \\
\text { orogênicas que caracterizam a região }\end{array}$ \\
\hline $\begin{array}{l}\text { Uso do Solo / } \\
\text { ARMANI } \\
(2010)\end{array}$ & $\begin{array}{l}\text { Atualmente } \\
\text { constitui-se unidade } \\
\text { de conservação }\end{array}$ & $\begin{array}{l}\text { No entorno há predomínio de mata em } \\
\text { regeneração, agricultura de pequeno porte e } \\
\text { fragmentos de plantios de eucalipto. No passado } \\
\text { houvera domínio, primeiramente, dos plantíos de } \\
\text { café, e em seguida, predominância do pastoreio. } \\
\text { Tais usos submeteram toda a região do Vale do } \\
\text { Paraíba e setores de ambas as serras ao } \\
\text { desmatamento e prejuízos ecológicos }\end{array}$ \\
\hline
\end{tabular}

Climaticamente destacam-se ao menos dois fundamentais aspectos zonais e regionais que incrementam a discussão sobre os dados:

1) um, referente a escala espacial e temporal mais abrangente, a posição do Estado de São Paulo no contexto zonal de circulação, circunscrito entre sistemas de frentes tropicais e polares, equatoriais e tropicais, em função de sua localização transicional em termos latitudinais e continentais, gerando um espaço de análise ideal (TARIFA, 1975), e

2) outro, sobre a influência de contextos regionais e locais, dos quais se destaca a possível contribuição das brisas atuantes na região em articulação à província geomorfológica da Serra do Mar.

\section{b. Instrumentação e dados}


Os dados utilizados foram produzidos durante o período de 1980 a 1988 pela primeira estação meteorológica introduzida no L.H.F.W.E. De origem japonesa, o modelo de calda e hélice denominado AS-11Z gerou dados de velocidade, direção de ventos e calmarias, de forma que as velocidades foram trabalhadas em metro por segundo (sendo a acurácia do equipamento de $\left.0,5 \mathrm{~m} \cdot \mathrm{s}^{-1}\right)$, as direções foram obtidas em oito quadrantes diferentes (N, NE, E, SE, S, SW, W e NW), e as calmarias foram os períodos em que as velocidades não superaram os $0,5 \mathrm{~m} . \mathrm{s}^{-}$ ${ }^{1}$. Durante todo o intervalo de funcionamento, a estação esteve instalada a 6 metros de altura da superfície.

A operação deste anemógrafo foi interrompida no segundo semestre de 1988, período até o qual foi produzida a maior série histórica contínua e consistida de dados de vento diário de toda região da Serra do Mar em São Paulo. Após sua desinstalação, sucessivos anemógrafos e anemômetros passaram a registrar os fluxos de vento, contudo problemas de calibração, falta de manutenção, avaria e perda de registros, além da própria diferença de acurácia, precisão e saída de dados entre os equipamentos que vieram em seguida e o instrumento utilizado, foram aspectos que contribuíram para que o recorte temporal de análise acompanhasse a operação de uma única estação.

Assim, optou-se por essa delimitação para que erros e imprecisões de natureza técnica fossem minimizados, considerando que, o dado de vento, pela natureza do fenômeno, possui intrinsecamente característica caótica de difícil coleta e interpretação, a qual não deve ser incrementada por variações oriundas de outros aspectos.

A despeito da razão técnica pela escolha do recorte temporal, salienta-se que o período de dados deve ser considerado representativo apenas para o período amostral, evitando-se a simples extrapolação de padrões de circulação e oscilação para décadas anteriores e posteriores, o que exige série histórica mais longa e contínua, e consistência destes dados.

À época da coleta, todos os três tipos de dados (velocidade, direção e calmaria) foram sistematizados por período diário, ou seja, as intensidades de ventos organizadas em velocidades médias diárias; e a direção de fluxos dada em porcentagem do tempo, sendo o período de calmaria considerado outra direção (direção 0). Assim, para um dia com 50\% de calmarias, tinha-se o registro de direção para as 12 horas restantes.

Para uniformizar o trabalho com as direções de vento excluíram-se as calmarias das medições de direção de fluxo, analisando-as à parte, como uma terceira característica de ventilação. Desta forma, a soma dos intervalos de predominância de cada direção passou a totalizar $100 \%$ do tempo de um dia. Este recurso permitiu analisar as direções comparativamente entre si, a evolução das calmarias e a articulação entre essas informações.

\section{c. Procedimentos de análises de dados}

Tarifa (1975) pontuou que o Estado de São Paulo, enquanto ambiente de estudo climatológico, está submetido, em termos zonais, à alternância de sistemas polares e tropicais, cujas predominâncias condicionam as características dos atributos climáticos. Reorganizada constantemente pela sucessão de massas e frentes, a dinâmica atmosférica tende à estabilidade nos períodos mais frios; e o inverso nos intervalos de verão e primavera. Assim, a interpretação das estruturas de movimentação dos fluxos com respaldo nesta abordagem permite analisar o grau de interferência dos sistemas zonais sobre o regime de ventos do Núcleo.

Fundamentados em tal assertiva, definiu-se três unidades cronológicas interpretativas para os dados, além da média global, sendo elas: anual, sazonal e mensal. A partir destas, então, procedeu-se com o cálculo da média para cada um dos itens de ventilação anteriormente mencionados, ressaltando as médias das velocidades de vento, as porcentagens de participação de cada direção de vento e das calmarias.

Embora a organização dos dados separadamente permita derivar informações sobre as intensidades dos fluxos e sobre direções predominantes, este procedimento de análise não esclarece os mecanismos de compensação aos quais dizem respeito os fluxos atmosféricos.

No intento de melhor identificar processos de balanceamento contidos nas movimentações atmosféricas, procedeu-se com a integração e sincronização dos diferentes dados, articulando as intensidades de velocidades e os períodos de calmarias aos diferentes setores de vento. Daí, pode-se realizar uma série de considerações sobre a relação intensidade e frequência das diferentes direções de ventos, e dessas em função dos períodos de calmarias agregados. 


\section{RESULTADOS}

\section{a. Direções de vento}

Os dados globais de direção de vento estão expostos na Figura 02, bem como as respectivas amplitudes de participação, considerando as médias mensais. Caracterizou a distribuição das médias da série histórica, a homogeneidade de participações dos diferentes setores e o desequilíbrio das amplitudes.

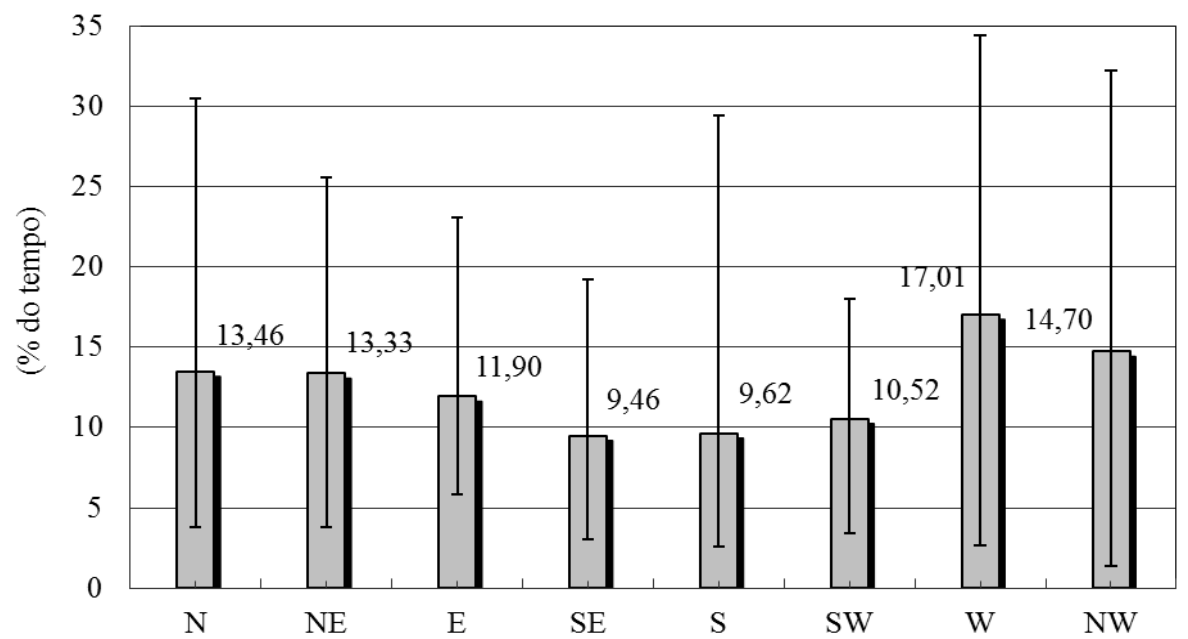

Figura 02 - Distribuição média em porcentagem do tempo de cada direção e respectivas amplitudes (médias máximas e mínimas).

O quadrante oeste demonstrou a maior participação porcentual no total de fluxos com $17 \%$ do tempo. Seguindo a tendência de predomínio dos quadrantes interiores, NW apresentou cerca de $15 \%$, seguido de perto por fluxos de $N$, cujo percentual foi de $13 \%$. As maiores amplitudes mensais coincidiram com os setores de frequências, indicando uma contribuição majoritária e menos concentrada.

Setores oceânicos como E, SE e S tiveram, por outro lado, contribuições menos expressivas comparativamente aos demais, constituindo pouco menos de $21 \%$ do total, contrapondo-se ao que se esperava encontrar como predominante na região.

Ano a ano os resultados apresentaram enorme variação, indicando um regime pouco homogêneo em sua evolução anual para o período considerado (FIGURA 03).

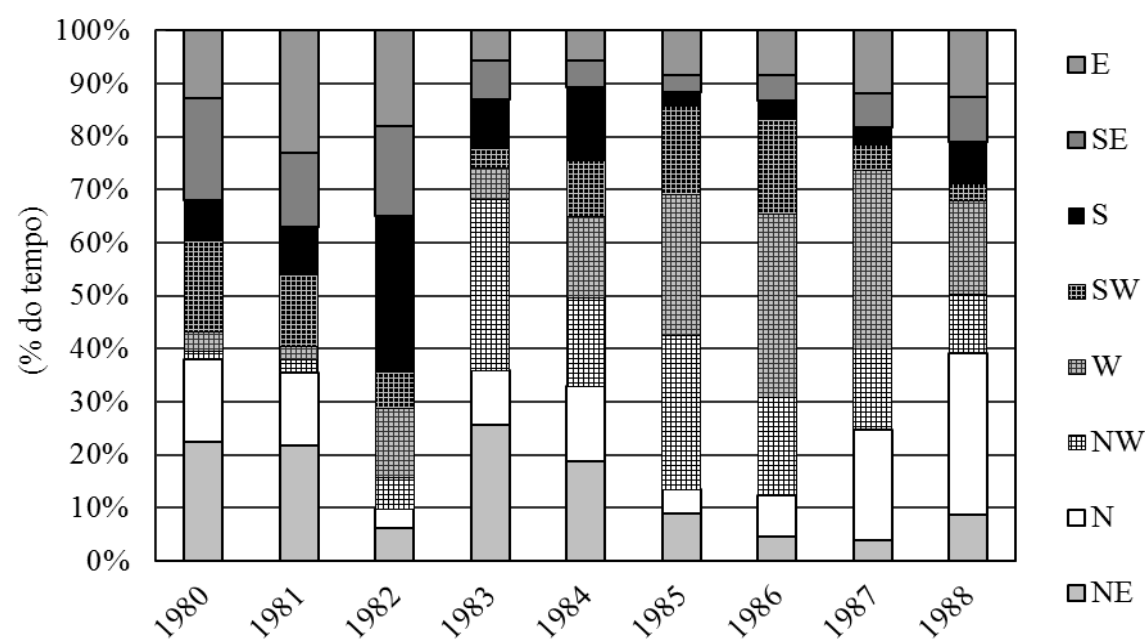

Figura 03 - Distribuição da frequência relativa (\%) anual de cada direção nos totais registrados.

A Figura 03a evidencia, ao menos dois intervalos diferentes. Um primeiro com predomínio de fluxos de E, SE, S e SW entre 1980 e 1982, e pico neste último ano, com dominância de ventos de sul (30\%); e, outro, entre 1983 e 1988, onde houve ascendência e participação 
majoritária de fluxos de $\mathrm{W}, \mathrm{NW}, \mathrm{N}$ e $\mathrm{NE}$, cujos resultados chegaram a totalizar, na soma dos quadrantes, mais de $70 \%$ em 1987.

A Figura 03b expressa mais claramente a magnitude desta transição. A inclinação das retas de W, NW e N evidenciam tendência positiva dos fluxos destes setores e predominância, no final da série, de ventos continentais.

Ao distribuir os resultados anuais em períodos intra-anuais, as médias e tendências mensais apresentadas na Figura 04, indicam predomínio significativo dos fluxos de NW e W, durante todo o ano, com breves oscilações.

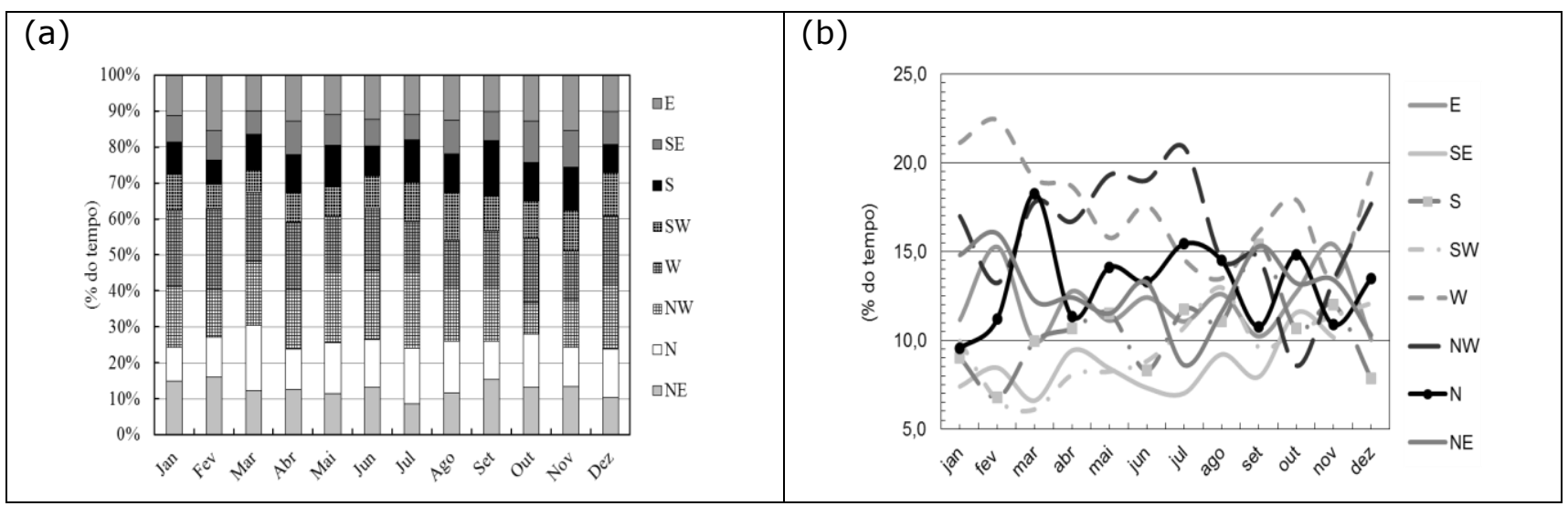

Figura 04 - Contribuição mensal dos diferentes setores de vento.

A participação mensal homogênea de cada um dos setores no total de fluxos (Figura 04a), evidencia o predomínio oriundos de $\mathrm{W}, \mathrm{NW}, \mathrm{N}$ e $\mathrm{NE}$, que somam, frequentemente, porcentagens superiores a $60 \%$.

De outra forma, na Figura 04b percebe-se com mais clareza a veemente participação de ventos de $W$ e NW entre janeiro e julho, período em que, dado o predomínio dos fluxos ocorreu concentração das direções prioritárias de vento.

Entre agosto e novembro, embora as mesmas direções continuassem predominando, observou-se certa desconcentração, com distribuição mais equitativa das diferentes direções, evidenciando uma ampliação de fluxos de S, SW e E.

Sazonalmente, as evoluções anuais das participações das direções de vento assemelham-se à distribuição observada para todo o período (FIGURA 3), com predomínio de fluxos de E, SE, SE, e SW, entre 1980 e 1982, e dos fluxos continentais entre 1983 e 1988, sendo que tal modificação é acentuada nas estações mais quentes, particularmente no verão.

Esta configuração permite deduzir que as intensas modificações ocorridas no regime entre 1982 e 1983 não possuem origem em anomalias relativas a alguma sazonalidade especificamente, tratando-se, portanto, de uma transformação de origem global dos dados, que envolve todo o período.

Segundo a Figura 05, o verão foi a estação que apresentou a mais destacada participação de fluxos de W e NW, totalizando cerca de $40 \%$ dos fluxos; e a menor contribuição de ventos originados de SW, S e SE.

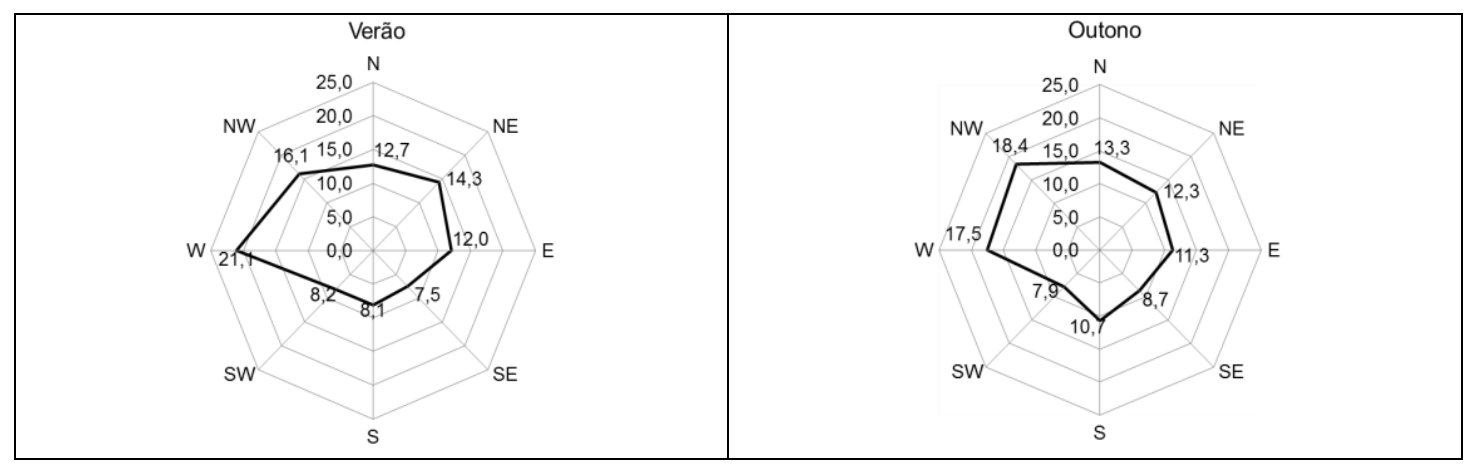



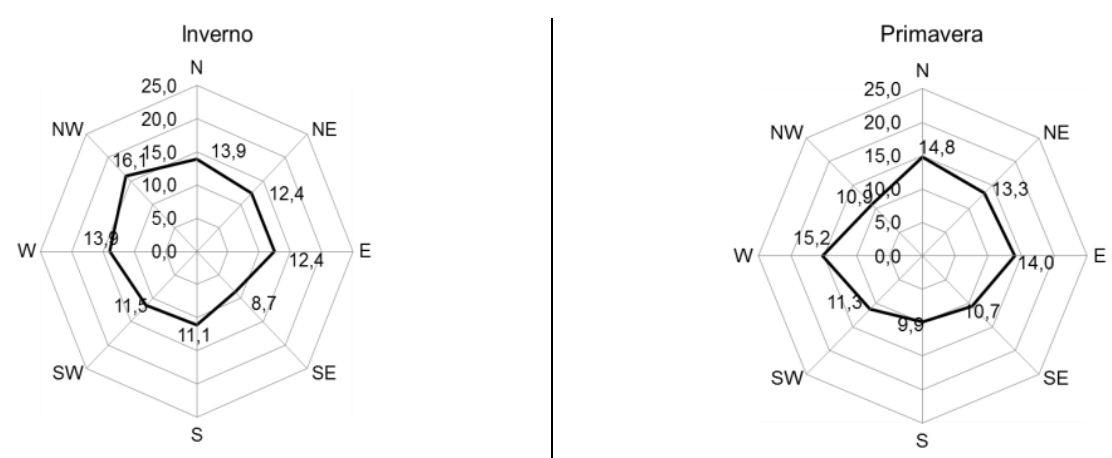

Figura 05 - Direção dos ventos por estação do ano.

Contrapondo-se à estação mais quente, o inverno obteve distribuição homogênea entre os setores, porém, novamente, com destaque aos ventos oriundos de NW e W.

O outono, acompanhando a distribuição relativa ao verão, obteve sobressalente participação de fluxos continentais (W e NW), e restrita contribuição de ventos de SW. A primavera, por sua vez, foi a única estação que apresentou retração dos ventos de NW e expansão dos ventos de SE e E.

b. Velocidades de vento

A média global das velocidades de vento foi igual a $2,0 \mathrm{~m} \cdot \mathrm{s}^{-1}$, equivalente a uma brisa fraca na escala de Beaufort.

TABELA 01 - Velocidades médias e médias máximas anuais e seus desvios padrão.

\begin{tabular}{ccccc}
\hline Ano & $\begin{array}{c}\text { Velocidade } \\
\text { Média }\end{array}$ & $\begin{array}{c}\text { Desvio } \\
\text { Padrão }\end{array}$ & $\begin{array}{c}\text { Velocidade } \\
\text { Média } \\
\text { Máxima }\end{array}$ & $\begin{array}{c}\text { Desvio } \\
\text { Padrão }\end{array}$ \\
\hline $\mathbf{1 9 8 0}$ & 2,5 & 0,42 & 5,3 & 1,4 \\
$\mathbf{1 9 8 1}$ & 1,8 & 0,24 & 4,3 & 1,2 \\
$\mathbf{1 9 8 2}$ & 1,7 & 0,43 & 4,2 & 1,3 \\
$\mathbf{1 9 8 3}$ & 2,1 & 0,39 & 5,0 & 1,1 \\
$\mathbf{1 9 8 4}$ & 1,1 & 0,15 & 2,2 & 0,6 \\
$\mathbf{1 9 8 5}$ & 1,7 & 0,57 & 3,0 & 1,0 \\
$\mathbf{1 9 8 6}$ & 3,0 & 0,65 & 5,0 & 1,3 \\
$\mathbf{1 9 8 7}$ & 3,4 & 1,52 & 5,2 & 1,2 \\
$\mathbf{1 9 8 8}$ & 1,0 & 0,38 & 2,3 & 1,1 \\
\hline TOTAL & $\mathbf{2 , 0}$ & & $\mathbf{4 , 0 6}$ & \\
\hline
\end{tabular}

Tabela 01 - Velocidades médias e médias máximas anuais e seus desvios padrão.

O ano de 1987 foi o de maior média para velocidade de vento, com 3,4 m.s ${ }^{-1}$, sendo acompanhado também do maior desvio padrão da série histórica, 1,52, apontando para um regime heterogêneo e descontínuo, constituído de momentos de maior e menor intensidades de vento. $\mathrm{O}$ ano seguinte apresentou a menor média anual de $1,0 \mathrm{~m} . \mathrm{s}^{-1}$,

O regime de intensidades brandas dos ventos do Núcleo Cunha é demonstrado na concentração das velocidades (Figura 06). A distribuição evidencia fluxos de baixas velocidades, agrupados na faixa entre 1,0 e $1,5 \mathrm{~m} . \mathrm{s}^{-1}$. As faixas imediatamente anterior (entre

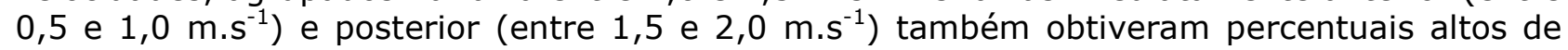
incidência de $16 \%$ e $19 \%$, respectivamente. A soma dos valores percentuais das três classes mencionadas se refere a mais de $55 \%$ do total de dias com valores entre 0,5 e $2,0 \mathrm{~m} \cdot \mathrm{s}^{-1}$. 


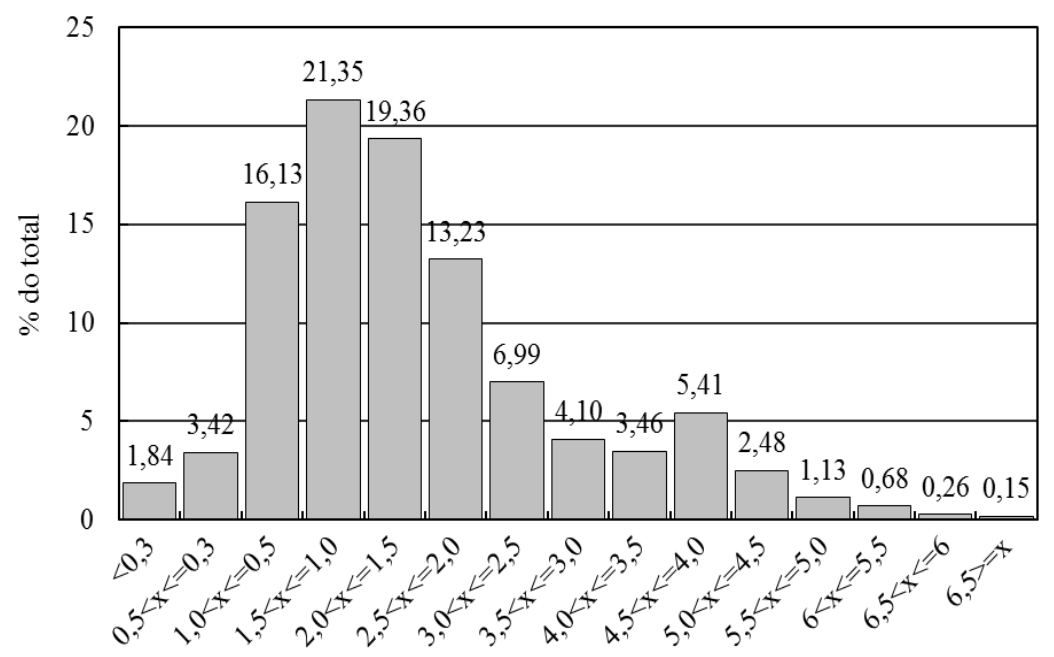

Figura 06 - Classes de velocidades médias em relação à percentagem de dias.

Mensalmente, as velocidades apresentaram oscilação entre janeiro e outubro, com variação não uniforme ao longo do ano, conforme Figura 07.

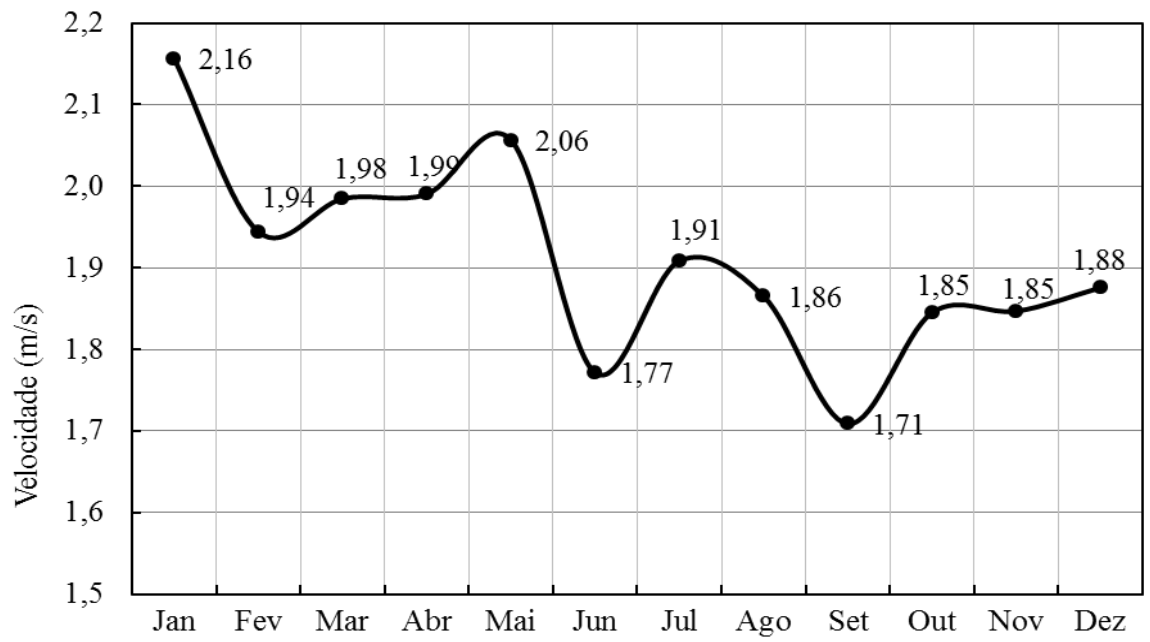

Figura 07 - Evolução das médias mensais das velocidades de vento.

Janeiro apresentou a maior média de velocidade de vento, 2,16 m.s ${ }^{-1}$. Setembro, por sua vez, obteve a menor média de velocidade de vento, com 1,7 m. $\mathrm{s}^{-1}$. Os meses compreendidos ora tiveram intensidades relativamente mais altas, como em maio e julho, ora mais baixas, como em fevereiro e junho. De modo geral, a tendência negativa cessa em setembro quando os valores de velocidade média passam a novamente ascender em outubro.

Considerando as estações a oscilação também é percebida, porém com menor intensidade. Chama atenção, no entanto, a modificação acentuada no padrão dos dados de vento a partir de 1984, com ascendência das velocidades com pico no verão de $1987\left(4,5 \mathrm{~m} . \mathrm{s}^{-1}\right)$, e posterior diminuição dos valores, até atingir o menor valor estacional na primavera de $1988\left(0,5 \mathrm{~m}^{-1} \mathrm{~s}^{-1}\right)$, conforme a Figura 08. 


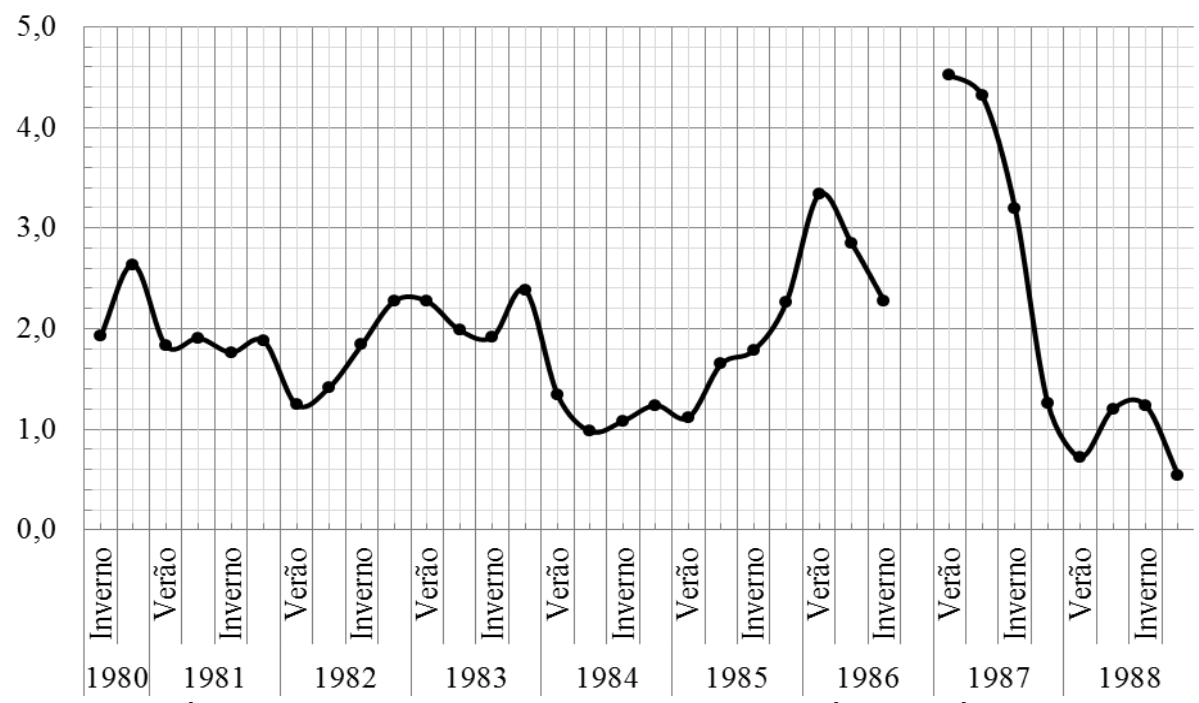

Figura 08 - Velocidades Médias e sua evolução sazonal dentro da série histórica.

Destaca-se na Figura 09 a ascensão das velocidades após o verão de 1985, a queda seguida da interrupção dos dados na primavera de 1986 e a brusca diminuição das velocidades médias em 1987, permitindo assim afirmar que, para as intensidades de vento, os padrões do regime são marcados por excepcionalidades.

\section{c. Dinâmica de vento}

Em média, as calmarias ocorrem em $58 \%$ do total de tempo registrado pela estação. Além do alto percentual sem movimentação do ar, os dados demonstram que houve tendência à diminuição dos fluxos entre 1980 e 1988 (FIGURA 09).

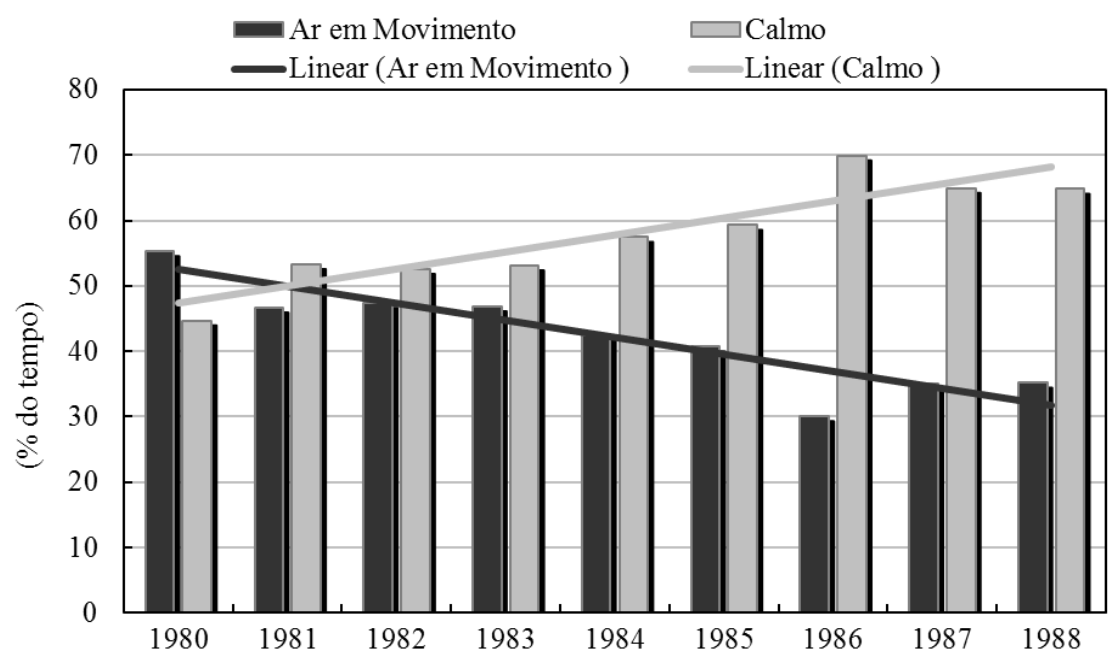

Figura 09 - Evolução anual das calmarias e movimentações de vento e respectivas linhas de tendência.

Enquanto no primeiro ano da série os movimentos do ar representavam $56 \%$ do tempo, em 1988 eles não totalizavam 36\%. Uma ampliação de 20\% das calmarias, com pico em 1986 quando atingiu cerca de $70 \%$. Podemos apontar este aspecto de variação dos dados como mais uma excentricidade do regime de ventos do Núcleo Cunha. As informações contidas na Figura 10 corroboram a enorme frequência de intervalos sem circulação. 


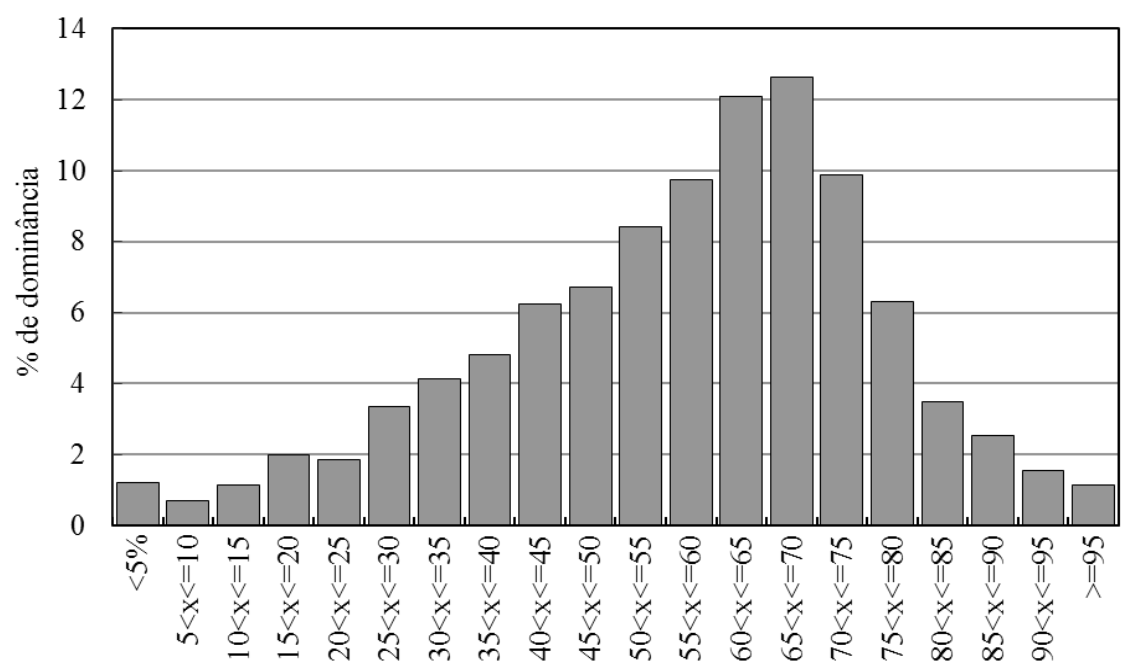

Figura 10 - Classes de porcentagem de tempo com calmarias.

Com acúmulo dos dados nas colunas que compreendem $60 \%$ e $70 \%$ do tempo com calmarias, a Figura 10 evidencia a distribuição desproporcional deste aspecto que, de modo geral, distingue o Núcleo Cunha como sendo um espaço particular, aparentemente, menos sujeito à turbulência horizontal do ar, frente a outras regiões do Estado de São Paulo (FARIA, 2000; AZEVEDO, 2004; MUNHOZ e GARCIA, 2008; LIMA e GALVANI, 2008; HACKEROTT e GANDU, 2010).

Mensalmente a evolução da dinâmica de ventos possuiu um período de predominância evidente das calmarias e outro momento houve recuo deste dado (FIGURA 11).

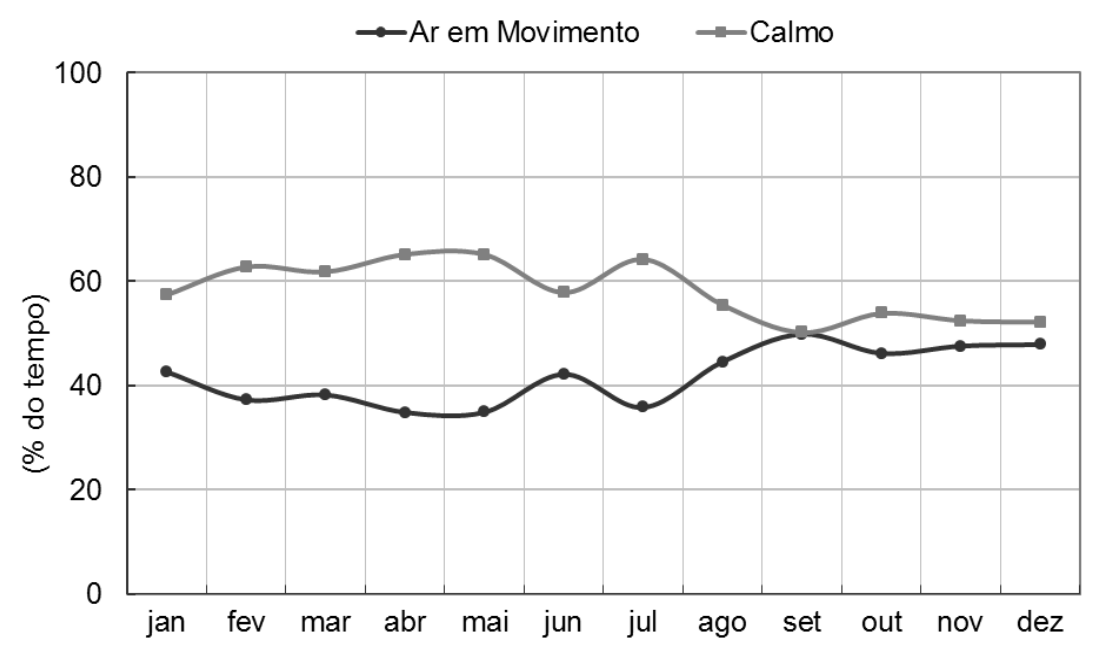

Figura 11 - Médias mensais das calmarias e da movimentação do ar.

Entre janeiro e julho as calmarias permaneceram frequentemente acima dos $60 \%$ do tempo. Apenas com o final do inverno e na primavera ocorreu estreitamento entre as duas curvas chegando a se tocarem em setembro, evidenciando que, neste mês, houve maior constância de movimentação atmosférica.

Analisando-se a evolução anual das sazonalidades, fica evidente, novamente, uma modificação astronômica dos dados de calmarias, mais precisamente a partir do sexto ano da série, em 1985 (FIGURA 12). 


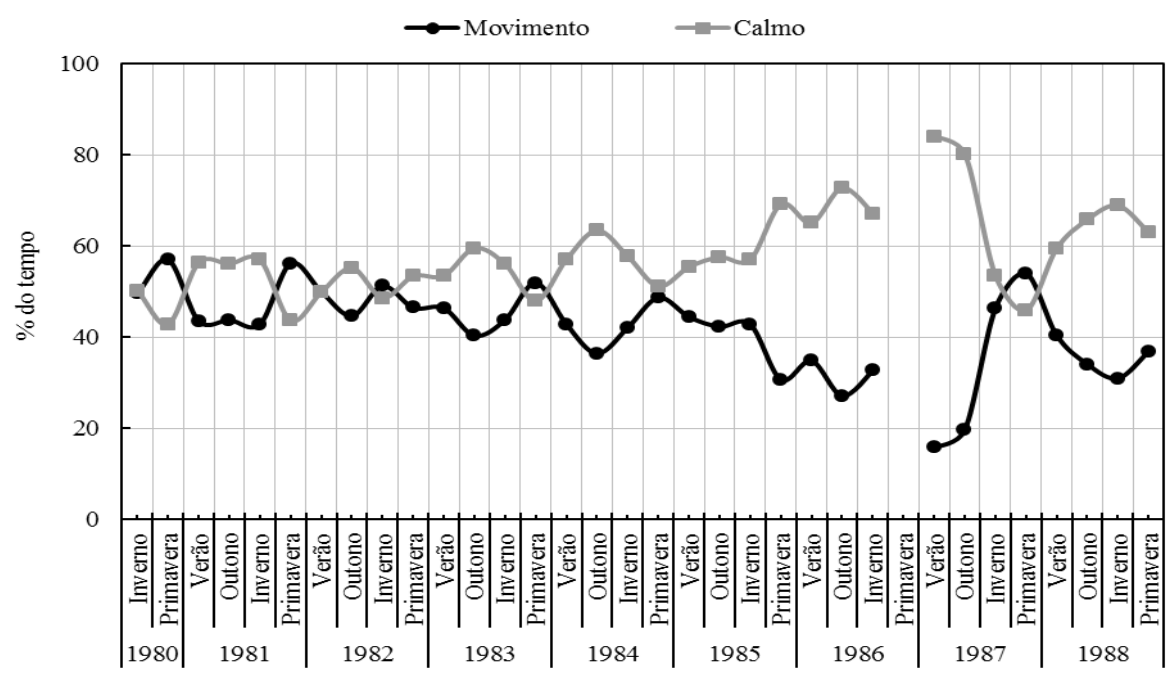

Figura 12 - Médias mensais apresentadas ano a ano das calmarias e da movimentação do ar.

Marcado por uma oscilação que evidencia um constante aumento das movimentações de ar nos períodos de primavera, o regime de calmarias da Figura 13, após o ano de 1985 passou a ser marcado não mais pelas oscilações sazonais, mas, sobretudo, pela aguda ascensão das calmarias, com pico no verão de 1987 , quando atingiu $84 \%$ do tempo. Na sequência deste mesmo ano, o regime apresentou um declínio súbito dos intervalos de "calmo", que somente voltou a crescer no verão do ano seguinte.

\section{d. Análise integrada}

Associando, primeiramente, as maiores velocidades de vento mensais às respectivas direções predominantes, obteve-se que sudoeste, com 2,9 m.s ${ }^{-1}$, apresentou o maior valor médio, seguido de outra direção continental: W, conforme se observa na Figura 13. As mais brandas velocidades foram referentes às direções $E$, SE e $S$, compreendidas entre 1,5 e 1,7 m.s ${ }^{-1}$.

-Velocidades Médias $\quad$ Frequência de ocorrênias

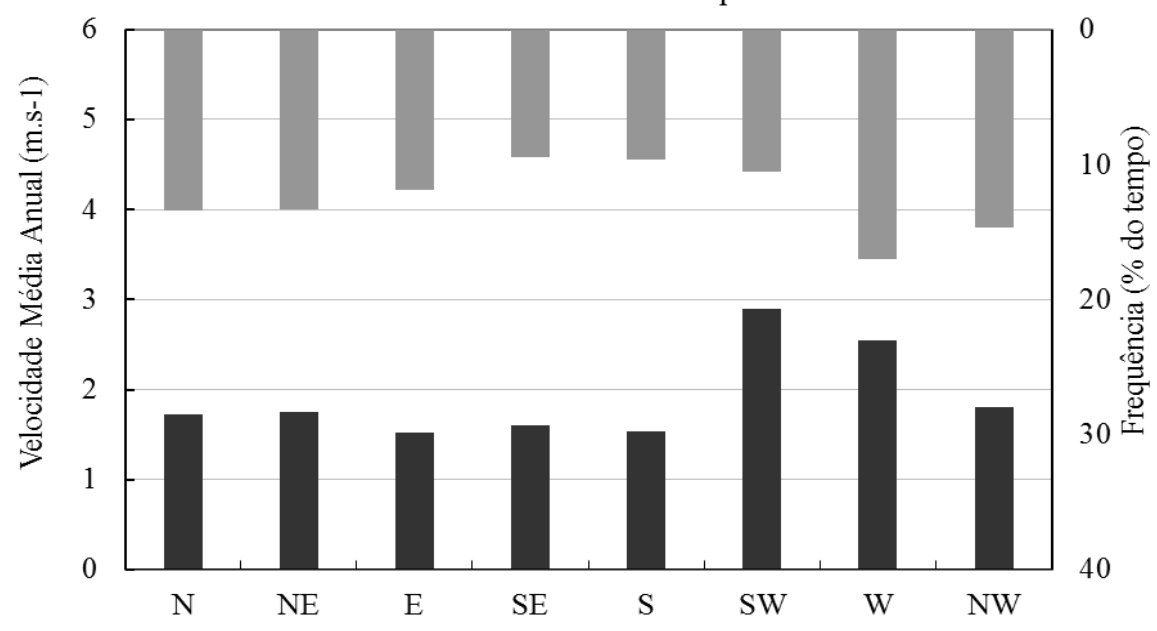

Figura 13 - Velocidades médias e freqüências de permanência dos ventos considerando os diferentes quadrantes.

Apesar do alto valor atribuído à direção SW, ponderando-se este resultado em relação a sua freqüência de ocorrência, tem-se um regime inconstante, não preponderante, e de fluxos mais intensos que as demais direções. Em relação a oeste, por sua vez, os valores de velocidade e de frequência indicam que esta direção é predominante no regime de ventos.

Por outro lado, os valores médios mensais de calmarias vão de encontro às direções predominantes mensais, particularmente W, NW e SW (FIGURA 14). 


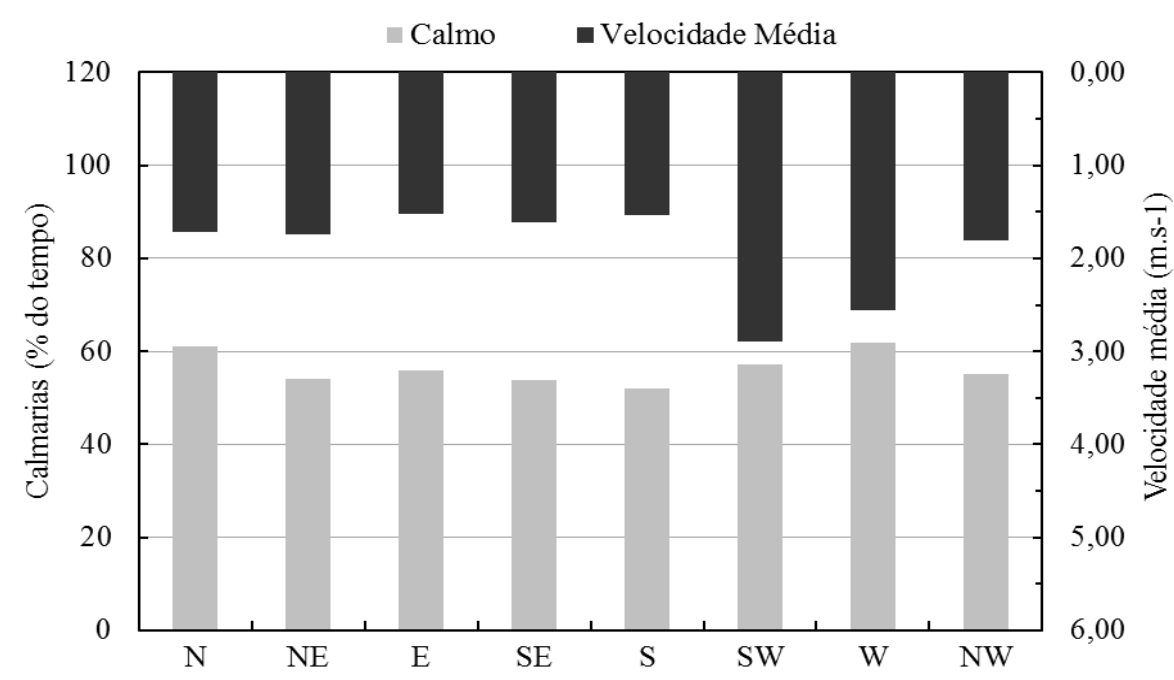

Figura 14 - Distribuição das calmarias (\%) e das velocidades médias $\left(m \cdot s^{-1}\right)$ em função das direções.

A Figura 14 atenta para a concomitância entre os intervalos médios mensais de calmarias e as velocidades médias mensais, respectivas à ocorrência de cada direção predominante. Assim, quando das vezes em que oeste fora considerada direção tônica mensal, a média de velocidade foi aproximadamente $2,8 \mathrm{~m} \cdot \mathrm{s}^{-1}$ e o período de calmarias equivalente a $63 \%$ do tempo.

Destaca-se na Figura 14 os baixos percentuais de calmarias relativos às direções de velocidades mais brandas, como leste, sudeste e sul, evidenciando a constância de circulação quando tais direções são predominantes.

Em função da excepcional ocorrência de fluxos de oeste na região serrana próxima ao litoral, resolveu-se investigar uma possível correlação entre este dado e as informações de velocidade e calmarias. Ao plotar estes dados em evolução anual, acentuou-se a simultaneidade da ascendência relacionada às calmarias e ao predomínio de ventos de oeste (FIGURA 15).

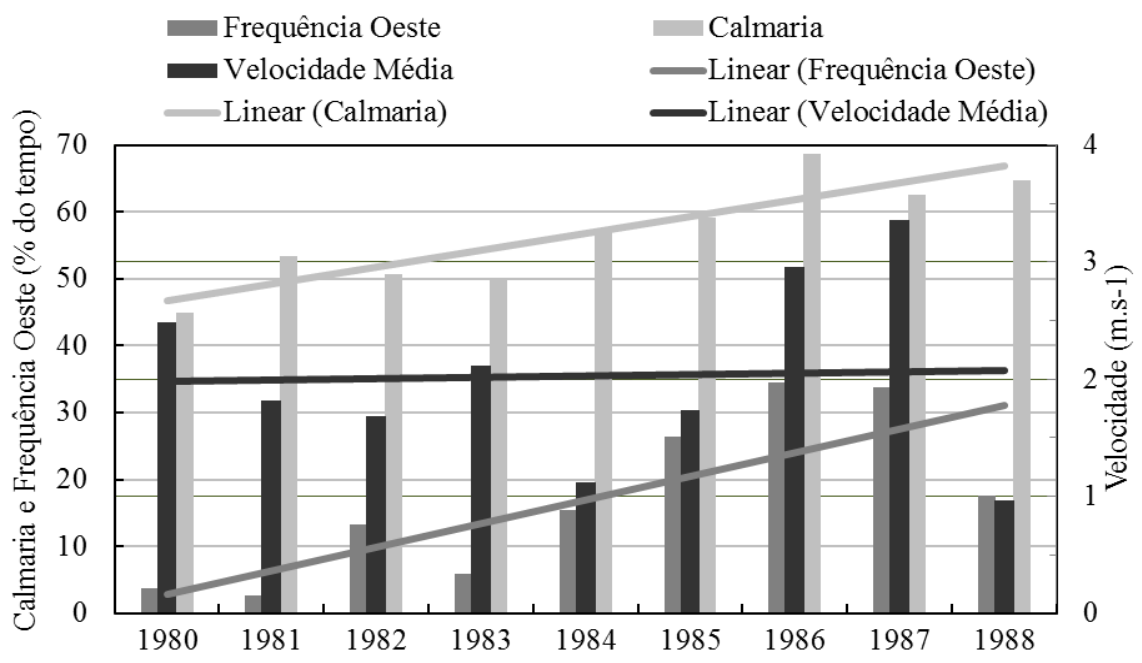

Figura 15 - Evolução anual das calmarias (\%), frequências de oeste (\%) e das velocidades médias $\left(\mathrm{m} . \mathrm{s}^{-1}\right)$ na série histórica.

Considerando que é possível haver na região alternância entre fluxos marítimos e continentais, e polares e tropicais, confrontou-se os regimes de calmarias e velocidades aos de predominância de fluxos continentais e oceânicos, conforme a Figura 16. 


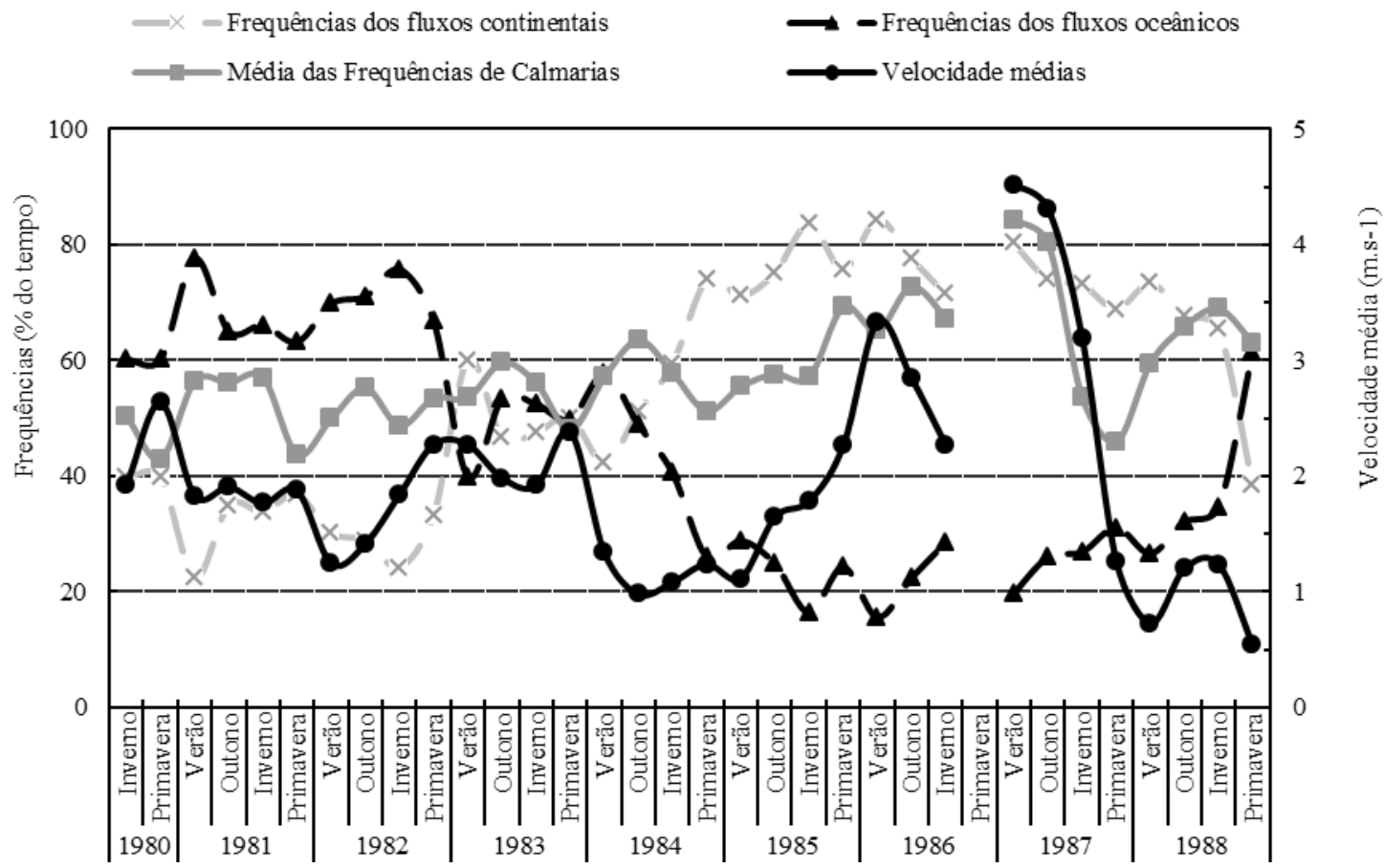

Figura 16 - Velocidades médias e frequência sazonais das calmarias, dos ventos continentais (SW, W, NW e N) e oceânicos (NE, E, SE e S).

Embora as oscilações sazonais dificultem a correlação entre as diferentes variáveis, a Figura 16 explicita participação majoritária de fluxos oceânicos entre 1980 e 1982, seguido de um período de alternância que perdurou de 1983 a 1984. Após este último ano, houve sobressalente crescimento dos fluxos de oeste, que chegaram a atingir $84 \%$ no inverno de 1985 e no verão de 1986, passando a descender, efetivamente, somente na primavera do último ano da série.

Na Figura 16 fica evidente o aumento dos valores de calmarias, velocidades médias e fluxos de oeste, particularmente, entre 1984 e 1987, com forte queda após este ano. Estes dados permitem-nos afirmar que o regime esteve sujeito a um período em que se ventilou menos, com fluxos brevemente mais intensos, especialmente oriundos de oeste.

\section{DISCUSSÃO}

Em relação às direções predominantes de vento, os setores destacados como de maior participação percentual, contrapuseram-se aos resultados esperados inicialmente.

Em função da proximidade do litoral e a evidente atuação das brisas em setores continentais em várias regiões do Estado de São Paulo, constantemente confirmada por diversos autores (PEZZOPANE et al., 1996; FARIA, 2000; LÓPEZ, 2001; AZEVEDO, 2004; LIMA e GALVANI, 2008; HACKEROTT e GANDÚ, 2010), fluxos de SE, E e S são comumente obtidos como predominantes. No entanto, a participação majoritária de ventos continentais, com destaque para o período entre 1984 e 1987, aponta para a restrição do sistema de brisas a altura da estação no Núcleo Cunha. Este resultado vai, parcialmente, ao encontro dos resultados obtidos por Libault (1972) no mapa de circulação atmosférica regional, cujos dados de vento por ele abordados, para as estações próximas ao Núcleo Cunha, indicaram baixa ocorrência de fluxos de S, SE e E.

Embora apontar apenas a interferência da Serra do Mar como um dos fatores que limitam os ventos de oceano seja vago, é inevitável considerar que o sistema escarpado do front atue de modo particular sobre os ventos de leste e sudeste, ascendendo-os, causando resfriamento adiabático e condensação, e assim, possivelmente restringindo suas contribuições em Cunha. De outro modo, esta mesma participação parece sujeitar a circulação da baixa troposfera na altura do Núcleo ao regime de brandas intensidades de vento e de altos percentuais de calmarias, novamente corroborando os resultados encontrados por Libault (1972).

$$
\text { Ano } 9 \text { - Vol. } 12 \text { - JAN/JUL } 2013
$$


Considerando esse desempenho da Serra do Mar é provável que os fluxos continentais se sobressaiam aos oceânicos em função do bloqueio topográfico imprimido pela escarpa. Esse exercício corrobora o fato de que ventos continentais são, prioritariamente, acompanhados de altas taxas de calmaria, constituindo um quadro de pouca circulação, de baixas velocidades e, aparentemente, com predomínio de oeste.

Assim, sugere-se que o contrário também pode ser verificado. Quando as participações dos setores oceânicos são acentuadas, as intensidades de vento tendem a um breve aumento e os percentuais de calmarias à redução. Desta forma, a Figura 16 fundamenta este mecanismo descrito de compensação de fluxos.

Entretanto, considerando o sistema de brisas como sendo extremamente regularizado, dado seu mecanismo universal de funcionamento e a participação da Serra do Mar uniforme e constante, variações anuais excepcionais, como a constatada nos diversos gráficos apresentados, são incomuns e difíceis de serem explicadas somente a partir de dados de uma única estação.

A inexistência, ainda, de ciclos sazonais ou mensais, bem definidos vai à contramão do que se espera para uma região que sofre forte influência de fatores constantes e/ou estáticos como são os descritos até o momento.

Tais considerações têm múltiplos desdobramentos: (1) contesta o mecanismo de atuação associada das brisas e da escarpa que produziu os resultados globais apresentados; (2) que as alterações dos regimes de ventos derivam de modificações atmosféricas relacionadas ao ritmo da circulação zonal ou supraregional; (3) que estas mesmas alterações sejam, na verdade, relativas à transformação do espaço local, ocasionada seja pela modificação das instalações da estação, seja pela construção de novas edificações, entre outras coisas; ou ainda (4), que não há ocorrência de canalizações de fluxos em função do entalhe e direcionamento de vales profundos e alinhados frequentes na região da Serra do Mar, uma vez que, esta interferência, antes de tudo, deveria significar assiduidade de um eixo/sentido particular de ventos, o que não fica expresso nos resultados.

Tais hipóteses deverão ser investigadas em trabalhos futuros a partir de abordagens tomadas em rede, com escalas mais abrangentes, no qual o foco será a análise de circulação regional.

\section{CONCLUSÕES}

Para o período de 1980 e 1988, o regime de ventos do Núcleo Cunha obteve predominância de fluxos de continente, notadamente oeste $(17 \%)$ e noroeste $(14 \%)$, minimizando a hipótese inicial de participação das brisas marítimas. Este mesmo predomínio ocorre para as unidades cronológicas mensais e sazonais, com a ocorrência esporádica de uma ou outra direção. Não foram identificados pelos gráficos regimes cíclicos sazonais que viabilizasse a análise de atuações de sistemas atmosféricos sobre a circulação local.

Com intensas variações anuais, porém com tendência positiva, as velocidades médias foram brandas para o período, sendo igual a 2,03 m.s. $\mathrm{m}$. O ano de 1987 apresentou a maior velocidade média $\left(3,3 \mathrm{~m} \cdot \mathrm{s}^{-1}\right)$ e após forte queda, o ano de 1988 obteve a menor velocidade, menos de $1,0 \mathrm{~m} \cdot \mathrm{s}^{-1}$.

Já para a escala sazonal e mensal, o verão obteve velocidades mais intensas, as quais reduziram de modo não uniforme até atingir seu valor mínimo em setembro. A turbulência atmosférica ocasionada pelo excedente de energia no verão e a estabilidade trazida pelo inverno e início da primavera satisfazem os resultados globais obtidos.

Relativo à dinâmica atmosférica constata-se que as calmarias são predominantes ( $58 \%$ do tempo), permitindo afirmar que sistemas atmosféricos locais sejam, possivelmente, produtores de estabilidade atmosférica, considerando que o ritmo de alternância de massas e frentes predominantes à altura do trópico e o sistema de brisas, habitualmente, são responsáveis por turbulência constante e regimes de ventos frequentes.

Entre 1980 e 1988 os períodos de movimentação do ar tendem a diminuir gradualmente, e as calmarias saem de $45 \%$ em 1980 , chegando a $65 \%$ em 1988, com cume em 1986, quando atinge $70 \%$. Sazonalmente os "calmos" são mais importantes entre janeiro e agosto, com destaque para o outono, atenuando-se nos meses seguintes a setembro, indicando maior movimentação do início da primavera até meados do verão.

Por último cabe destacar que, não há ciclos identificáveis nos regimes anuais e mensais (ou sazonais) para qualquer das variáveis analisadas. Por outro lado, embora tenha sido 
quantificada, as retas de tendência denunciam correlação da evolução anual e sazonal entre o módulo "direção de ventos" e as calmarias, indicando para uma alteração global do ritmo dos dados, notadamente, entre 1984 e 1987.

Foram identificados dois sentidos para esta relação: (1) que aponta para um maior período de calmarias quando ventos de continente são predominantes; e (2), seu contrário, que indica para uma ampliação das movimentações atmosféricas e acentuação das intensidades de vento quando aumentam as contribuições dos fluxos de oceano. Nota-se apenas que, estas mesmas correlações, no entanto, têm as velocidades de vento como coadjuvantes.

A partir da abordagem integrada dos dados conclui-se ainda que:

- SW embora tenha apresentado as maiores médias de velocidade de vento $\left(2,9 \mathrm{~m} \cdot \mathrm{s}^{-1}\right)$, sua contribuição foi pouco expressiva no total de participação das direções de vento. Ao contrário desta direção, W e NW apresentaram valores de freqüência e intensidade altos, que relevam seus papéis no regime;

- mensalmente as maiores velocidades vinculam-se, novamente, à direção $W$ entre janeiro e agosto. A partir de setembro as direções que comportam as velocidades mais altas variam entre S, SE, NE e NW. Sazonalmente, a variação das frequências de calmarias e das velocidades de vento possuem relações não precisas, com algum destaque à simultaneidade das oscilações observadas.

\section{REFERÊNCIAS BIBLIOGRÁFICAS}

ARMANI, G. Análise topo e microclimática tridimensional em uma microbacia experimental de clima tropical úmido de altitude. 2010. $123 \mathrm{f}+3$ volumes. Tese (Doutorado em Geografia Física) - Departamento de Geografia, Faculdade de Filosofia, Letras e Ciências Humanas, Universidade de São Paulo, São Paulo.

ARMANI, G. Interações entre a atmosfera e a superfície terrestre: variações da temperatura na bacia B do núcleo Cunha (IF) - SP. 2004. 198 f. + anexos. Dissertação (Mestrado em Geografia Física) - Departamento de Geografia, Faculdade de Filosofia, Letras e Ciências Humanas, Universidade de São Paulo, São Paulo.

AZEVEDO, T. R. Por uma abordagem adequada do vento em geografia. In: Seminário de Pesquisa em Geografia Física, 2., 2004, São Paulo, Resumo... São Paulo, Universidade de São Paulo, 2004.

$A Y O A D E$, J. O. Introdução à climatologia para os trópicos. Rio de Janeiro: Bertrand Brasil, 1986, 332p.

CICCO, V. Análise de séries temporais hidrológicas em microbacia com cobertura vegetal natural de mata atlântica, Cunha - SP. 2004. 124 f. Dissertação (Mestrado em Geografia Física) - Departamento de Geografia, Faculdade de Filosofia, Letras e Ciências Humanas, Universidade de São Paulo, São Paulo.

$\mathrm{CICCO}, \mathrm{V}$. Determinação da evapotranspiração pelos métodos dos balanços hídrico e de cloreto e a quantificação da interceptação das chuvas na Mata Atlântica: São Paulo, SP e Cunha, SP. 2010. 138 f. Tese (Doutorado em Geografia Física) - Departamento de Geografia, Faculdade de Filosofia, Letras e Ciências Humanas, Universidade de São Paulo, São Paulo.

CONTI, J. B. Circulação secundária e efeito orográfico na gênese das chuvas na região nordeste paulista. 1975. 82 f. Tese (Doutorado em Geografia Física) - Faculdade de Filosofia, Letras e Ciências Humanas, Universidade de São Paulo, São Paulo.

FARIA, J. R. G. Caracterização do vento na camada intra-urbana da cidade de Bauru - SP. In: XI Congresso Brasileiro de Meteorologia, 2000, Rio de Janeiro, Anais... Rio de Janeiro, 2000. Acesso em: 20 de novembro de 2010.

FURIAN, S. M.; PFEIFER, R. M. Levantamento de reconhecimento do meio físico do Núcleo Cunha, SP. Boletim Técnico do Instituto Florestal, v. 40, n. 2, p.183 - 193, dezembro de 1986.

GALVANI, E.; KLOSOWSKI, E. S.; CUNHA, A. R.; da; MARTINS, D. Caracterização da direção predominante do vento em Maringá - PR. Revista Brasileira de Agrometeorologista, Santa Maria, v. 7, n. 1, 1999.

HACKEROTT, J. A.; GANDU, A. W. Comparação dos padrões de vento de superfície entre Caraguatatuba (SP) e Cachoeira Paulista (SP). In: XVI Congresso Brasileiro de Meteorologia, 2010, Belém-PA, Anais... Belém-PA, 2010. 
LIBAULT, A (Coordenação). Mapa de Circulação Atmosférica Regional (ventos). In: Atlas do Estado de São Paulo: Fascículo 1. São Paulo: Instituto de Geografia da Universidade de São Paulo. 1972. 1 mapa color., Escala 1:2000000. Prancha IV-3.

LIMA, N. G. B.; GALVANI, E. Variação da direção e velocidade do vento em função da presença de vegetação: os manguezais como estudo de caso. In: Simpósio Brasileiro de Climatologia Geográfica, 8., 2008, Alto Caparaó, Anais... Alto Caparaó/MG: Universidade Federal de Uberlândia, 2008.

LÓPEZ, C. C. O vento. In: Climas da cidade de São Paulo: teoria e prática. TARIFA J. R.; AZEVEDO, T. R. (Org). São Paulo: Pró-reitoria de cultura e extensão. Universidade de São Paulo: Laboratório de Climatologia. Faculdade de Filosofia, Letras e Ciências Humanas, Universidade de São Paulo. 2001. p. 112 - 126. (GEOUSP - Coleção Novos Caminhos, 4).

LUIZ, R. A. F. Classificação climática do núcleo Cunha do Parque Estadual da Serra do Mar, Cunha - SP. 2008. 103 f. Monografia (Trabalho de Graduação Individual) Departamento de Geografia, Faculdade de Filosofia, Letras e Ciências Humanas, Universidade de São Paulo, São Paulo.

MONTEIRO, C. A. F. A Frente Polar Atlântica e as chuvas de inverno na fachada suloriental do Brasil. 1969. 69 f. Tese. (Doutorado em Geografia Física) - Instituto de Geografia - Universidade de São Paulo, São Paulo, 1969.

MUNHOZ, F. C.; GARCIA, A. Caracterização da velocidade e direção predominante do vento para a localidade de Ituverava - SP. Revista Brasileira de Meteorologista, v. 23, n. 1, 2008. p. $30-34$.

NETO, J. L. S. Da climatologia geográfica à geografia do clima. Gênese, paradigmas e aplicações do clima como fenômeno geográfico. Revista da Anpege, UNESP, Presidente Prudente, v. 4, p. 51 - 72, 2008.

NIMER, E. Climatologia do Brasil. Rio de Janeiro: IBGE, Departamento de Recursos Naturais e Estudos Ambientais, 1989.

PLANO DE MANEJO DO PARQUE ESTADUAL DA SERRA DO MAR (PESM) SECRETAIA DO MEIO AMBIENTE - GOVERNO DO ESTADO DE SÃO PAULO. BRITO, M. C. W.; OLIVEIRA, L. R. C. N. de. (Org.). 2008.

Disponível em: <http://www.fflorestal.sp.gov.br/planodemanejoCompletos.php>

Acesso em: 15 de janeiro de 2011

PEZZOPANE, J. E. M.; ORTOLANI, A. A.; GODOY, G.; PEZZOPANE, J. R. M. Influência da brisa terra-mar no período de saturação da umidade do ar no interior de dois seringais de cultivo em Ubatuba (SP). Climatologia (Nota), Campinas, v. 55, n. 1, p. $201-205.1996$.

PEREIRA, A. R.; ANGELOCCI, L. R.; SENTELHAS, P. C. Agrometeorologia: fundamentos e aplicações práticas. Guaíba: Livraria e Editora Agropecuária, 2002, 478 p.

ROSS, J. L. S.; MOROZ, I. C. Mapa Geomorfológico do Estado de São Paulo: Escala 1:500000. Mapas e Relatório. São Paulo: Lab. de Geomorfologia Depto. De Geografia - FFLCH - USP/Lab. de Geotécnica e Geologia Aplicada - IPT / FAPESP, Volume 1, 1997. 64 p.

SÃO PAULO - SECRETARIA DE ENERGIA, RECURSOS HÍDRICOS E SANEAMENTO DO ESTADO DE SÃO PAULO. Mapa Geológico do Estado de São Paulo. São Paulo, 2005. 1 mapa, color., $60 \mathrm{~cm} \times 90 \mathrm{~cm}$. Escala 1:750000.

SANSIGOLO, C. A. Distribuição de extremos de precipitação diária, temperature maxima e minima e velocidade do vento em Piracicaba, SP (1917 - 2006). Revista Brasileira de Meteorologista, v. 23, n. 3, 2008. p. $341-346$.

TARIFA, J. R. Fluxos polares e as chuvas de primavera-verão no Estado de São Paulo: uma análise quantitativa do processo genético. 1975. 93 f. Dissertação (Mestrado em Geografia Física) - Instituto de Geografia, Universidade de São Paulo, São Paulo, 1975.

WALDHEIM, P. V.; SANTOS, I. A. Uma caracterização dos ventos em Santa Cruz para aplicação em poluição atmosfera. In: Congresso Brasileiro de Meteorologia, 13; 2004, Fortaleza; Anais... Universidade Federal do Ceará.

\section{AGRADECIMENTOS}

À toda equipe da engenharia florestal do Instituto Florestal do Estado de São Paulo, pela orientação e manutenção dos equipamentos em Cunha.

Ao professor Emerson Galvani pelas orientações e sugestões.

Ao CNPq pelo subsídio financeiro por meio da bolsa de iniciação científica. 